\title{
ALTERAÇÕES DA SILHUETA FEMININA: A INFLUÊNCIA DA MODA
}

\author{
DRA. DENISE CASTILHOS DE ARAUJO \\ Instituto de Ciências Humanas, Letras e Artes, Universidade \\ Feevale (Novo Hamburgo - Rio Grande do Sul - Brasil) \\ E-mail: deniseca@feevale.br
}

\section{DANIELE LEORATTO}

Instituto de Ciências Humanas, Letras e Artes, Universidade

Feevale (Novo Hamburgo - Rio Grande do Sul - Brasil)

E-mail: dani_leoratto.hotmail.com

\begin{abstract}
RESUMO
O presente artigo objetiva refletir a respeito da relação entre moda e corpo feminino, tendo como linha condutora mudanças ocorridas na silhueta das mulheres. Parte-se da hipótese de que a moda cria desejos e necessidades, sugerindo ao interlocutor a realização de mudanças e ajustes, adaptando a silhueta do corpo feminino. Parte-se de uma discussão teórica a respeito de corpo e moda, confrontando, posteriormente, esses dois temas. Posteriormente, há a realização da reflexão acerca de algumas imagens da revista Manequim e do jornal Zero Hora, entre os períodos de 1960 a 2000. Observou-se que realmente a mídia tem influenciado as formas dos corpos femininos, os quais, muitas vezes, devem se adaptar aos formatos das roupas sugeridos, para usarem roupas da moda.
\end{abstract}

PALAVRAS-CHAVE: Moda; corpo; mídia; mulher. 


\section{INTRODUÇÃO}

Neste artigo, discute-se a relação entre moda e alterações que ela pode causar na silhueta feminina. A escolha do tema justifica-se pela impressionante influência da moda, principalmente na alteração das formas dos corpos femininos, a qual pode ser verificada na sua história. Além disso, tal reflexão evidencia uma ligação íntima entre moda e corpo feminino, o que a torna atual e importante ao aprofundamento da temática, ainda pouco explorada.

As questões que norteiam a problemática desta pesquisa são: as tendências de moda lançadas deformam ou redesenham as silhuetas do corpo feminino? Como essas tendências, apresentadas nas revistas, são assumidas pelas leitoras?

Os objetivos deste trabalho são caracterizar o conceito de corpo e sua presença atual nos meios de comunicação e na moda; definir moda e sua história; relacionar moda e corpo, principalmente no que diz respeito à silhueta feminina; analisar imagens de editorias de moda e de jornais para verificar a influência da moda nas alterações da silhueta feminina.

Para a etapa de análise, optou-se por imagens de dois impressos, ou seja, editoriais de moda oriundos de revista especializada: Manequim, e de um jornal do RS: Zero Hora, da década de 1960 até os anos 2000.

O artigo apresenta-se em três partes: a definição de corpo, sua importância na sociedade e seu aspecto cultural; a seguir discute-se a respeito da moda, sua evolução e influências; posteriormente, analisa-se imagens de moda a fim de se verificar as sugestões que a moda realizou no que diz respeito às mudanças dos corpos femininos.

\section{SOBRE O CORPO}

Como linguagem' socioculturalmente construída, o corpo enuncia e presentifica valores. São inúmeras as manifestações teóricas a respeito da noção de corpo, que

[...] evidenciam a responsabilidade de permear diferentes pontos de vista a fim de demonstrar a circulação de posicionamentos e de críticas sobre a imagem do corpo no contexto contemporâneo (GARCIA, 2005, p. 2).

Aqui, toma-se a noção de corpo como meio de significação, ou seja, ele é um corpo cultural, passível de modificação.

I. Linguagem é o uso de um determinado sistema de signos, de qualquer natureza, o qual serve para a comunicação (ANDRADE; MEDEIROS, 2004). 
No período da Pré-história até a Idade Média, havia a concepção de homem "como um ser inteiramente constituído de Natureza e de essência divina" (SILVA, 200 I , p. 7), a Natureza, o corpo e a essência divina, a alma, compreendidos como interdependentes na vivência do homem. Esta relação era bastante evidente nas tradições judaico-cristãs, que buscavam a virtude do indivíduo, de forma que a divinização se sobrepunha aos desejos do corpo, o qual deveria se submeter à razão, rejeitando toda forma de prazer e paixões. Ele era menosprezado por ser suscetível a essas pulsões, o que traria consequências negativas para sua imagem como ser humano² (SILVA, 200 I). Essa visão de homem foi repensada na Idade Moderna, quando ele se tornou um "corpo individual" (SILVA, 200 I, p. I2), e não mais uma força unicamente divina.

A transformação do corpo em algo que pode ser conhecido e mensurável é, também, sua transformação em algo que pode ser dominado. A dessacralização do corpo aponta para sua ambiguidade no interior da cultura ocidental: é importante enquanto fonte de experiência, mas, é, também, o corpo que se desvaloriza na medida em que se pode mexer nele e alterá-lo (SILVA, 200I).

Com essa visão surge a perspectiva da "importância do corpo como fonte de experiência humana no mundo" (SILVA, 200 I, p. 12), abre-se a possibilidade do homem interferir nele, de reconstruí-lo e ressignificá-lo. O corpo é o suporte da identidade do indivíduo, sua personificação no mundo, é a estrutura básica que estabelece as primeiras relações do ser com outras esferas. Pode-se entendê-lo como meio de interação com o contexto sociocultural, "pois o corpo já é um dos canais de materialização do pensamento, do perceber e do sentir circundante" (CASTILHO, 2009, p. 43).

O corpo também é signo, pois através dele o homem transmite mensagens através de sinais não verbais. "O corpo constrói manifestações textuais que se deixam apreender e significar por efeitos de sentido que produzem" (CASTILHO, 2009, p. 44); ele se faz meio de expressão, articula significados e se expressa através de interações com o meio social, cultural, ambiental, político em que está inserido.

O corpo que mais sofre influências do meio social tem sido o feminino e, segundo Del Priore (2000, p. 15), "a identidade do corpo feminino corresponde ao equilíbrio entre a tríade beleza-saúde-juventude [...] essas são basicamente as três condições culturais da fecundidade, portanto, da perpetuação da linhagem. Em todas as culturas a mulher é o objeto de desejo". Viu-se no decorrer do tempo que a mulher tomou para si o controle de seu corpo, principalmente na década de

2. Trata-se da relação corpo-alma como consequência de qualquer ato do ser humano que refletiria sobre ele como indivíduo social, ocasionando em um julgamento negativo sobre ele. Buscava-se exaltar a alma como forma de controlar as pulsões do homem. 
1960. Apesar desse fato, ainda se percebe resquícios de submissão, não mais aos homens, mas, agora, às exigências da sociedade, e à busca de uma imagem corporal específica. Por outro lado, o mercado coloca-se como auxiliador nessa busca realizada pelas mulheres, pois oferece recursos como: medicamentos, aparelhos de ginástica, roupas, enfim, vários produtos para alcançar o ideal corporal sugerido/ exigido na sociedade e desejado por várias mulheres.

A cultura midiática tem criado/estabelecido imagens de beleza, muitas vezes ilusórias, nos textos veiculados pela mídia, através do uso de dublês de corpos, de ferramentas que alteram o formato físico (photoshop), disfarçando imperfeições, retocando indivíduos, o que parece não ter importância para os consumidores desses textos. Algumas mulheres, por outro lado, esperam alcançar o padrão estético ditado pelas passarelas de moda, os corpos exibidos pelas Top Models. Tem-se conhecimento que estas mulheres apresentam características anoréxicas, reveladas pelo excessivo emagrecimento de braços, pernas, rosto; além disto, muitas delas apresentam imperfeições em seus corpos, em virtude de dietas altamente restritivas, justificadas pela exigência do mercado. Etcoff ( 1999) considera as top models anomalias, pois até mesmo essas modelos têm imperfeições em seus corpos.

O interessante é que, apesar de as pessoas terem consciência disso, e dos riscos que a saúde pode sofrer, ainda assim, esse padrão estético é o desejo de muitas mulheres.

Kehl e Bucci (2004, p. 176) afirmam que:

Para milhares de brasileiros, incentivados pela publicidade e pela indústria cultural, o sentido da vida reduziu-se à produção de um corpo. A possibilidade de "inventar" um corpo ideal, com a ajuda de técnicos e químicos do ramo, confunde-se com a construção de um destino, de um ramo, de uma obra.

Então, a possibilidade desse corpo ideal é a meta da maior parte da população, entretanto é sobre a população feminina que as exigências recaem com maior força. São as mulheres, as consumidoras mais desejadas e seduzidas pela indústria da estética e beleza. Ou seja, para a mulher, manter-se dentro de padrões estéticos é mais extenuante que os rígidos e apertados espartilhos usados décadas atrás.

Nas sociedades modernas, pode-se caracterizar a beleza corporal como sendo um fato social, pois há, notoriamente, uma busca coletiva por um corpo belo, embora haja diferentes construções desse corpo, em diversas sociedades e grupos sociais.

Para Andrade (2003), a imagem do que é saúde e do que é beleza, no decorrer do século $X X$, sofreu um deslocamento em relação aos conceitos de períodos anteriores. Conquistar um corpo saudável e belo é um objetivo individual 
a ser atingido. Para tanto, é preciso um exercício intencional de autocontrole, o qual envolve força de vontade, restrição e vigilância constantes.

As modificações realizadas pelo indivíduo sobre o corpo são resultado da cultura, são processos interativos com a sociedade podendo, estas interferências, serem "queridas ou necessárias" (CASTILHO, 2009, p. 46). No triângulo corpo, gestualidade e elementos de decoração, inclui-se o vestuário, através da livre expressão do homem (CASTILHO, 2009). E, como elementos decorativos, tem-se as primeiras noções de cobertura e vestuário para o ser humano, a pele.

A epiderme é o primeiro tecido que veste o homem, é nela que ficam registradas definitivamente as marcas das relações do indivíduo. "A roupa, por sua vez, veste o corpo, recobrindo-lhe como uma segunda pele, o que the confere uma constituição anatômica muito diversa" (CASTILHO; MARTINS, 2005, p. 86). E, exercendo seu papel comunicador, a roupa interage com o corpo buscando novos sentidos para o sujeito, uma ressignificação para o próprio corpo.

A roupa constrói-se como linguagem e, como tal, altera a estrutura física do corpo, imprimindo em sua plástica novos traços, linhas, volumes e cores. Essa caracterização que o traje traz ao corpo é o que faz com que os sujeitos executem performances para a aquisição desses elementos que vão revestir sua massa corpórea (CASTILHO; MARTINS, 2005).

A roupa é uma extensão do corpo, ela representa de forma temporária o que o corpo quer comunicar, podendo-se moldar aos desejos do indivíduo de forma fácil. A essas oscilações temporárias, denomina-se moda. A relação moda e corpo da seguinte maneira: "A moda, enfim, é regida por contínuas operações de transformação do parecer do corpo sobre o ser (corpo biomorfológico)" (CASTILHO; MARTINS, 2005, p. 83).

A visão estética alterou-se de períodos em períodos, construindo imagens a serem idealizadas e conquistadas. Braga (2005b, p. 19) afirma que "desde que o homem é homem, ele sempre vem privilegiando um determinado padrão de beleza que se torna o ideal por um período de tempo ou para uma cultura".

Na Pré-História, valorizava-se a opulência das formas do corpo. Já na Grécia Antiga o ideal era o de harmonia, com formas equilibradas e proporcionais. Durante o século XII, possuir o ventre saliente era tido como padrão estético (BRAGA, 2005b). No século XVI, a atenção era dada para a parte superior do corpo: rosto, ombros e busto. As características marcantes eram a "delicadeza da tez, a intensidade dos olhos, a regularidade dos traços” (MORENO, 2008, p. I 5). Já nos séculos seguintes, a ênfase recaía sobre as pernas, quadris e cintura. Durante os séculos XVII e XVIII, "a beleza apropria-se dos recursos de embelezamento e o padrão vigente é aquele que se utiliza de artifícios como perucas, perfumes, etiqueta social, maquiagem em excessos visuais, etc." (BRAGA, 2005b, p. 52). 
No século XVIII, era valorizado o conjunto da silhueta, buscava-se uma beleza individual e singular. Durante o século XIX, o corpo curvilíneo e a cintura fina se tornaram os ideais de beleza (MORENO, 2008). O século $X X$ foi marcado por mudanças bruscas e em menor espaço de tempo. Em 1920, a silhueta se tornou geometrizada, reta. Durante a década de 1950, resgatou-se a feminilidade, marcando a cintura da mulher.

As atenções se voltam para o universo feminino durante a década de 60, que traz grandes mudanças não apenas se falando de beleza. Ansiando por independência, as mulheres desse período buscavam por liberdade e individualidade.

Independentes, as mulheres da década de 70 conquistaram espaço na sociedade e, consequentemente, receberam grande visibilidade. $O$ papel da mulher se transformou, passou a tomar suas próprias decisões, não sendo mais tão subordinada ao homem como o era no passado. Assumindo seu espaço, a mulher afirmou-se como sujeito e seu corpo acompanhando esse movimento de "saída da mulher da obscuridade [...] tornou-se visível, desejado" (ARAUJO; SCHEMES, 2009, p. 12), servindo, também, como norteadores dos padrões estéticos.

Nos anos 80, a busca por um corpo perfeito passou a ser uma obsessão: adoção de hábitos saudáveis, rotina de exercícios, uma boa alimentação, etc. É perceptível nesse momento "que a atenção maior, muitas vezes, é dada à possibilidade do corpo servir como precioso veículo para a manifestação de uma série de preocupações e características e reflexos sociais da época" (ARAUJO; SCHEMES, 2009, p. 13). O corpo se torna símbolo de status, é o principal meio de representação do indivíduo, mas, também, passa a ser um diferenciador social, ele é analisado, rotulado e fortemente apreciado.

Na contramão da busca por uma imagem perfeita e irreal, a década de 90 buscou a valorização da individualidade e dos "excluídos" pelos padrões estéticos vigentes, trazendo como ideais a serem alcançados a "magreza anoréxica, a ambiguidade da androginia e o exótico" (BRAGA, 2005b, p. 2I). "Como é natural a negação de um valor e a aclamação de um normalmente oposto, a mudança de milênio traz à moda aspectos de saúde e a revalorização das formas torneadas do corpo" (BRAGA, 2005b, p. 22). Assim, atualmente, como afirma Santaella (2004, p. 127), o corpo deve ser forte, belo, jovem, perfeito, ou seja, o culto ao corpo surge com força, e o indivíduo aprisionado a este sistema que a autora chama de "corpo-objeto".

Com todas as intervenções que o corpo sofre na busca do perfeito, acaba por transformar sua identidade, tornando-se mero objeto à disposição dos desejos e pulsões do indivíduo. Pensa-se aqui, a identidade como possível de transformações, pois, para Silva (2000, p. 108), "esta concepção de identidade não assinala aquele núcleo estável do eu que passa, do início ao fim, sem qualquer mudança, por todas 
as vicissitudes da história." Então, essas alterações são tomadas como corriqueiras, uma vez que o indivíduo pode ter uma identidade fluida, transitória.

Sendo o corpo aberto a essas possibilidades de modificações, pode-se dizer que ele "é o suporte de marcas, deformações e mutilações ritualísticas de representações e, logicamente, o principal suporte humano das práticas discursivas" (CASTILHO, 2009, p. 83).

A reconstrução do corpo é impulsionada pela estética e pelo desejo de embelezamento. $\bigcirc$ corpo é objeto do narcisismo, ele é remodelado e modificado conforme as "necessidades" do indivíduo. Silva (200 I, p. 85) afirma que por essa atitude, "o corpo é, também por isso, um objeto de pertença, já que é coisificado por uma subjetividade dominadora".

É essa dominância do exterior sobre o interior que nos leva a compreender o poder que a glorificação e exibição do corpo humano passaram a assumir no mundo contemporâneo.

\section{SOBRE A MODA}

Moda é comportamento, é a maneira como o indivíduo interage com o meio. De origem latina, modus significa modo (BRAGA, 2005a); Barnard, por sua vez, indica que a palavra "fashion" (moda, tradução da língua inglesa) "remete ao latim factio, que significa fazendo ou fabricando [...], até facere, isto é, fazer ou fabricar" (BARNARD, 2003, p. 23), sendo aqui o sentido expresso como algo que é feito.

O conceito de moda surgiu no final da Idade Média, sendo delineado como "um diferenciador social, um diferenciador de sexo [...], como fator resultante da busca da individualidade [...] e, principalmente com o caráter de sazonialidade" (BRAGA, 2005a, p. 35).

À moda foram atribuídos alguns conceitos, tais como a efemeridade (BRAGA, 2005a), a procura pela diferenciação ou pela individualidade, o pudor e encobrimento, proteção e adorno (MIRANDA, 2008).

$O$ ato de vestir é repleto de significados e intenções, sendo elas conscientes ou inconscientes, como observa Fischer-Mirkin (200I), e o modo do indivíduo se comunicar com o meio também se dá através do vestuário, "as roupas, como artefatos, 'criam' comportamentos por sua capacidade de impor identidades sociais e permitir que as pessoas afirmem identidades sociais latentes" (CRANE, 2006, p. 22).

A moda é uma das formas de expressão do ser humano, e pode tanto ser profundamente reveladora como "pode ser um verdadeiro simulacro, podendo dizer a verdade ou enganar os olhos dos menos treinados" (BRAGA, 2005a, p. 17). A roupa é o objeto de comunicação da moda, pois carrega os seus símbolos; porém, a interação moda-indivíduo, não se restringe ao objeto, é um discurso complexo que se estende ao corpo. Segundo Castilho (2009, p. 34), 
A moda pode ser compreendida como a expressão de um conteúdo e, assim, ela pode ser lida como um texto, que, por sua vez, veicula um discurso. E o corpo, da mesma maneira, também, é a expressão de um conteúdo, isto é, um texto que veicula um discurso. Juntos moda e corpo formam a unicidade textual que sustenta um conteúdo, ou como disse, um determinado discurso.

A interação entre vestuário, contexto social, cultura e comportamento traduzem o significado implícito na escolha de moda do usuário; a moda é reflexo da sociedade, do que acontece no mundo e ao redor das pessoas (BRAGA, 2005a). Ela é dinâmica por receber forte influência do contexto em que se insere, modifica-se a partir do momento em que a cultura, a política, a economia e a sociedade sofrem transformações. Por outro lado, a moda também é uma forma de expressão pessoal, assim, o indivíduo faz suas escolhas, guiado não só por seus gostos, mas, também, pela realidade que o cerca.

A moda releva características de contextos e representa valores da sociedade. Este artigo trata-se somente da moda a partir da década de 1960, para estabelecer a relação entre moda e silhueta feminina. $O$ período inicial foi selecionado, pois a revista Manequim (uma das fontes de consulta) começou a circular no Brasil a partir de 1959; no entanto, somente os exemplares de 1960 estão digitalizados e disponíveis no site da editora, permitindo o acesso ao acervo.

Na década de 1960, a repressão fez crescer no jovem o desejo de se rebelar, a busca por liberdade de expressão e sexual; estes desejos se refletiram na moda (BAUDOT, 2002). "Nos anos 60, então, a moda refletia as aspirações da juventude. [...] A moda tornara-se democrática, liberada e unissex, respondendo a uma filosofia de vida muito crítica em relação ao presente recente e à sociedade de consumo" (MOUTINHO; VALENÇA, 2000, p. 190).

$O$ uniforme de luta dos jovens eram os blue jeans, roupas sem gravata e a jaqueta de couro (MOUTINHO; VALENÇA, 2000). A minissaia e o vestido tubinho foram algumas vedetes da moda. O psicodelismo e influências da pop art e da op art ${ }^{3}$ foram fortes. Com a conquista espacial, a moda futurista ganhou força, utilizando plástico, acrílico e estampas multicoloridas. As tendências da época seguiram uma linha dura e geométrica (LAVER, 1989). No final da década, surgiu o movimento hippie, com estilo relaxado, e elementos como: calças folgadas, túnicas, batas, tecidos rústicos, cores chamativas, florescentes, flores, estampas indianas (LAVER, 1989).

A mulher, independente e autoconfiante, buscou ascensão no mercado de trabalho, procurando dar ao traje uma aparência de seriedade, adotou blazers com

3. "Forma de arte que surgiu na década de 20, mas que entrou em moda, como padronagem de tecidos, na década de 60. [...] Os círculos, espirais e quadrados resultantes são dispostos de forma a criar ilusão óptica" (O'HARA, 1992, p. 198). 
saias ou calças, emprestando uma aparência masculina ao visual (MOUTINHO; VALENÇA, 2000). Usava cada vez menos maquiagem, preferindo um aspecto mais natural (NERY, 2004).

Baudot (2002) afirma que a partir da década de 1970 a moda apresentou uma aceleração considerável no seu ritmo, e ocorreram dois movimentos sociais importantes que afetam a moda: a volta à natureza e o movimento feminista. A moda se tornou democrática e revolucionária, houve experimentação de materiais, cores, formas e texturas: tecidos sintéticos e rústicos, estampas geométricas e florais, roupas unissex, saias curtas e longas, brilho, jeans e roupas esporte (LAVER, 1989).

A preocupação com o bem-estar e a saúde tornou-se bastante popular, bem como as caminhadas e as corridas. O estilo esportivo ganhou força, o uso de malhas, blusões de moletom, calças ajustadas de moletom foram bastante usadas. "O formato do corpo foi novamente revelado pelo tratamento das roupas que cobriam, como na década de 50, ao invés de o ser pela roupa que havia sido retirada" (LAVER, 1989, p. 270). O corpo foi realçado e a silhueta feminina modelada através do uso de tecidos de malha ou do corte das roupas. As nádegas, valorizadas pelo uso dos jeans e das calças apertadas se tornou a nova zona erógena. Esse movimento de preocupação com a saúde e a moda esportiva acabaram por tornar erótico o corpo esguio e em boa forma (LAVER, 1989). Também surgiu, na época, o punk, uma moda marginal, com calças e saias rasgadas, jaquetas de couro tachadas, correntes, piercings e cabelo espetado. (LAVER, 1989).

Na década de 1980, as roupas eram alegres, esportivas, versáteis, divertidas, sofisticadas, sensuais e ousadas. "A moda torna-se exageradamente cheia de contrastes" (MOUTINHO; VALENÇA, 2000, p. 26I). Os desejos eram de luxo, poder e status (BAUDOT, 2002).

Como características principais no vestuário estão cores contrastantes e cítricas, a cintura alta, ombreiras, roupas de moletom e cotton-lycra e a modelagem ampla (MOUTINHO; VALENÇA, 2000). Outras peças que marcaram o período: saia balonê, legging, vestido com fenda, tomara-que-caia, calça fuseau, collants, bermuda ciclista, moletom, tailleurs, jeans com elastano.

"Nos anos 90, a face do mundo se altera muito à medida que o século XXI se aproxima" (MOUTINHO; VALENÇA, 2000, p. 284). A moda tornou-se democrática, coexistindo a diversidade e a multiplicidade, falou-se em estilo e busca do conforto. "À força de eliminações sucessivas, de simplificações, de arrependimentos a moda dos anos 90 põe-se de acordo com um grito de guerra: minimalismo" (BAUDOT, 2002, p. 3 I8), que trouxe a praticidade proporcionada pela simplificação das roupas.

A silhueta ideal era o estilo manequim com braços e pernas finas, o qual passou a ser o ideal de beleza. Começou a era da cirurgia plástica, especialmente do 
silicone. O busto se tornou zona erógena, valorizado por decotes e transparências. A preocupação com a estética prevaleceu nessa década.

O século $X X$ terminou com a democratização da moda, proporcionando a livre escolha entre as múltiplas opções que a indústria da moda produzia, ela "torna-se "design do corpo, "projeto do movimento e da relação impessoal" (CALANCA, 2008, p. 209). A ausência de tendências e regras definidas para a vestimenta permitiu ao usuário optar de forma espontânea por seu vestuário de acordo com sua personalidade e gosto, levando em conta suas necessidades (MOUTINHO; VALENÇA, 2000).

A estética contemporânea exige um corpo perfeito, sendo este ideal personificado na figura das supermodelos. "Mas, na verdade, é mais como deusas do que como modelos que elas são apresentadas" (BAUDOT, 2002, p. 3 |9), tornando-se uma imagem imposta pela mídia. Em um movimento pós-moderno de culto ao corpo, esse corpo ideal é alcançado através de cuidados com a saúde, pelo esporte ou através de cirurgias plásticas.

A busca da perfeição a todo custo, por meio de artifícios que se aproximem do modelo ideal, evidenciam o simulacro como forte característica deste período; a identidade do indivíduo passa a ser caracterizada "pelo que é visível no corpo humano" (MESQUITA, 2004, p. 6 I). Lipovetsky (2004, p. 2 I) observa outros tipos de comportamentos presentes na sociedade atual: "monitoramento do peso, busca de informação sobre a saúde, ginástica".

Os conceitos de beleza do início do século XXl estão pautados puramente na estética: "os mais velhos quiseram rejuvenescer a todo o custo e copiaram os mais jovens, tanto na atitude como e, principalmente, na moda" (BRAGA, 2005a, p. 55).

Nesse quadro, o corpo contemporâneo é corpo flutuante, que se transforma como se fosse levado pela força indomável do desejo; quem opta pela diferença assume a fisionomia de um corpo 'pós-humano'. O corpo contemporâneo que muda coloca-se em uma encruzilhada entre o hipertecnológico e o neotribal. É um corpo in progress, pós-orgânico, que nasce da contaminação da tecnologia e carne, arcaísmos e metal, pele e tinta (CALANCA, 2008, p. 199).

\section{MODA E CORPO: RELAÇÕES ENTRE TENDÊNCIAS DE MODA E A SILHUETA DO CORPO FEMININO}

Neste tópico, identifica-se as alterações que o corpo feminino sofreu desde os anos 1960 aos 2000. Para isso, foram selecionadas, de forma aleatória, duas imagens 
veiculadas na mídia, uma de editorial de moda publicado em revista especializada, e outra divulgada por jornal, representando o uso e as adaptações que se fazia das tendências vigentes no período. A revista utilizada é a Manequim, ${ }^{4}$ e o jornal, Zero Hora. ${ }^{5}$

Esta análise quer responder duas questões: as tendências de moda lançadas deformam ou redesenham as silhuetas do corpo feminino? Outra indagação é a respeito da forma como as tendências de moda apresentadas nas revistas são assumidas pelas mulheres (leitoras), e as consequências em relação à possível alteração nas silhuetas. ${ }^{6}$ É importante lembrar que não há uma única silhueta feminina em cada período, mas há, sim, uma orientação das formas físicas que os corpos femininos deveriam ter em cada período representado pelas figuras selecionadas.

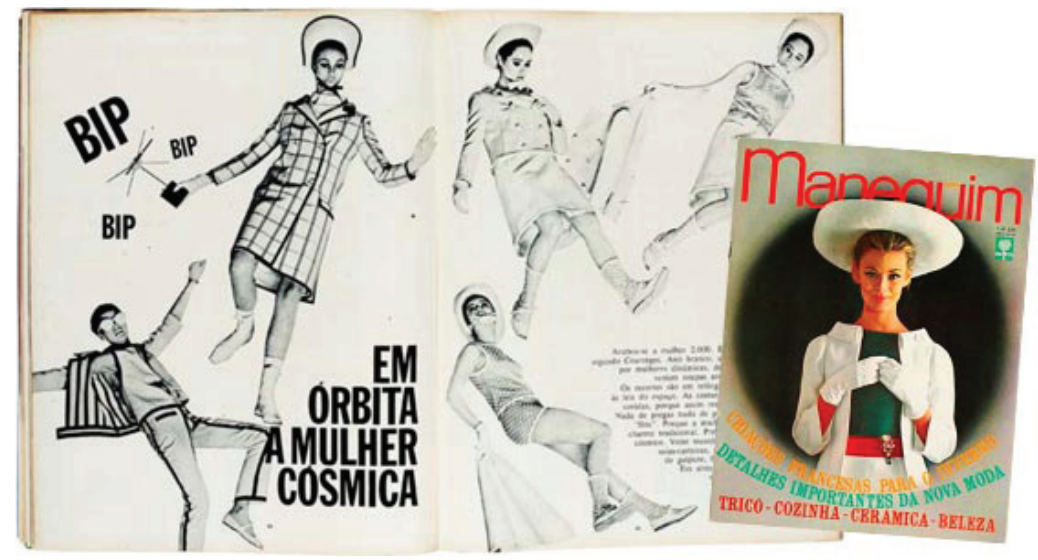

Figura I. Editorial de moda "Em órbita a mulher cósmica" e capa da revista Manequim dos anos 60 .

Disponível: http://manequim.abril.com.br/moda/ historia-da-moda/50-anos-da-modano-brasil/1960-pecas-3.shtml

4. A revista Manequim é uma revista feminina que aborda assuntos relacionados à moda, beleza, culinária, decoração, sendo destinada a profissionais da área e ao público em geral. Manequim foi criada em 1959, com publicação mensal pela Editora Abril.

5. O jornal Zero Hora é um veículo de circulação diária com abrangência em todo o território nacional. Foi fundado no ano de 1964 e pertence ao Grupo RBS.

6. Entende-se silhueta como sinônimo de imagem corporal, conforme proposto por Kakeshita (2008). 
A Figura I representa a corrida espacial que teve início na década de 1960, e a geometrização da forma, em detrimento dos formatos curvilíneos teve como origem o movimento de independência da mulher. A adoção de formas mais retas na vestimenta feminina pode ter sido a tentativa das mulheres se assemelharem física, intelectual, profissional e socialmente aos homens, escondendo sua silhueta, buscando se aproximar de referências masculinas em um movimento de conquista de seu espaço na sociedade. Além disso, conforme menciona Baudot (2002), essa foi uma década de rebeldia, de busca pela liberdade, a qual pode ser vista através da imagem das mulheres flutuando no espaço.

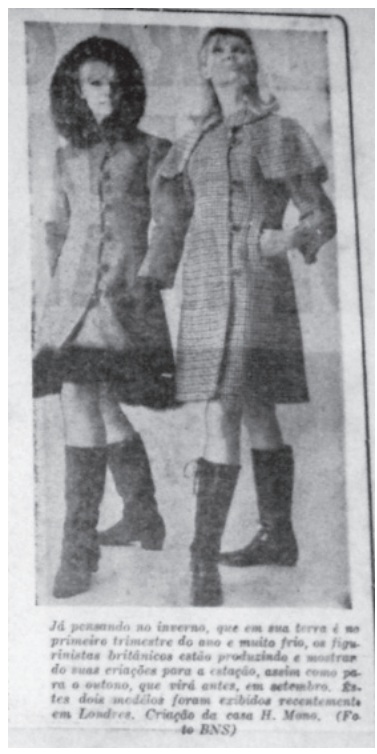

Figura 2. Coluna "O Mundo de Gilda", foto de modelos sugeridos para a estação.

Fonte: Zero Hora, n. 597, 1966.

Os modelos apresentados no jornal Zero Hora confirmam o uso da silhueta tubular e de modelos geometrizados durante a década de 1960, como mostra a Figura 2. Outro elemento marcante neste período são os comprimentos mini, bastante difundidos entre as mulheres. Formas mais amplas, afastadas do corpo, delineiam uma estrutura mais reta e descomprometida em mostrar a silhueta feminina.

Nos anos 70, tecidos leves e estampas com motivos étnicos, geométricos e florais são os principais elementos dos vestidos apresentados na Figura 3; a silhueta é fluída, as saias amplas, os comprimentos são longos. As peças, na parte superior, se ajustam aos contornos do corpo, revelando formas sensuais exclusivamente femininas, braços finos, a curva dos seios, as pernas, tornozelos, costas, consideradas zonas erógenas. O cenário e a atitude demonstram uma atmosfera de descontração alegre e colorida. 


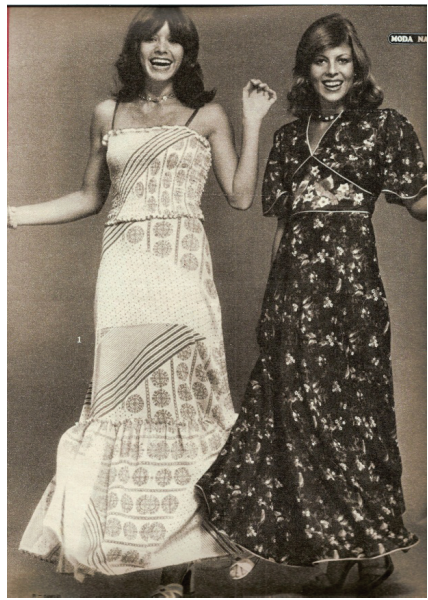

Figura 3. Editorial de moda revista Manequim anos 70.

Fonte: Manequim, n. 180, 1974.

A Figura 4 apresentada na coluna "Feminina" do jornal Zero Hora confirma a tendência do uso de tecidos leves, formas amplas e comprimentos longos nos anos 70. $\bigcirc$ modelo passa a impressão de silhueta alongada, porém, não mostra parte alguma do corpo e demarca apenas o busto.

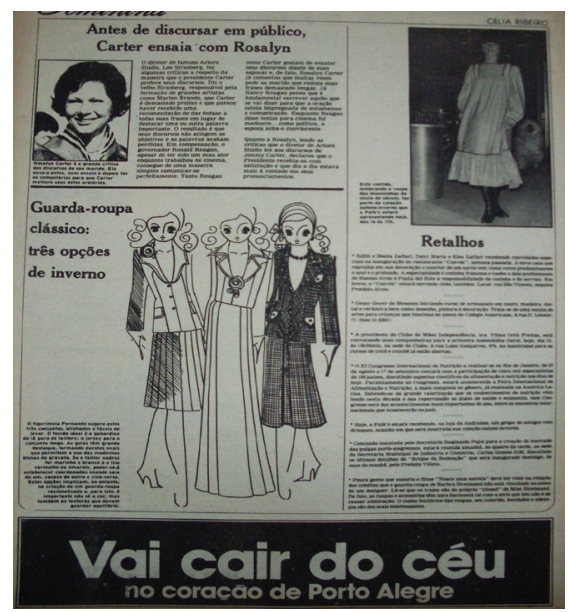

Figura 4. Coluna "feminina", foto de modelo sugerido para a estação.

Fonte: Zero Hora, n. 4556, 1978. 
Durante a década de 80, o culto ao corpo e a valorização dos esportes trouxe uma tendência de sportswear, ${ }^{7}$ amplamente divulgada e aceita: calça legging, calça fuseau, malhas, moletom,(MOUTINHO; VALENÇA, 2000). A modelo, na Figura 5, se posiciona como praticante de atividade física, reforçando essa ideia. As roupas são justas, as calças são "coladas" ao corpo, acompanhando todas as linhas e curvas femininas, insinuando sensualidade.

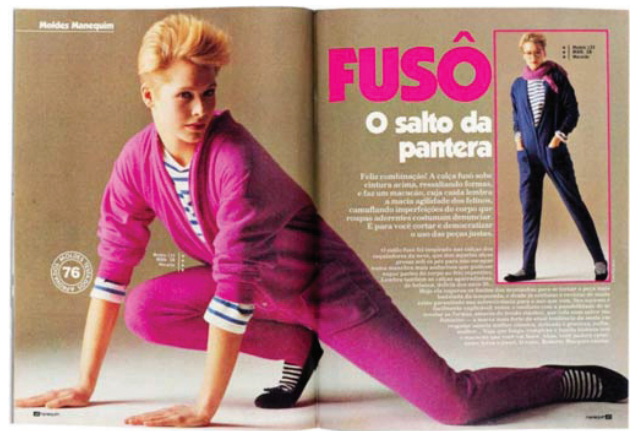

Figura 5. Editorial de moda revista Manequim anos 80.

Fonte: http://manequim.abril.com.br/moda/historia-da-moda/50anos-da-moda-no-brasil// 980-pecas-6.shtml.

A silhueta feminina era representada pela imagem de um triângulo invertido, foi deformada pelas formas amplas na parte superior e pelos ombros largos, em contraste com pernas finas e torneadas por calças justas.

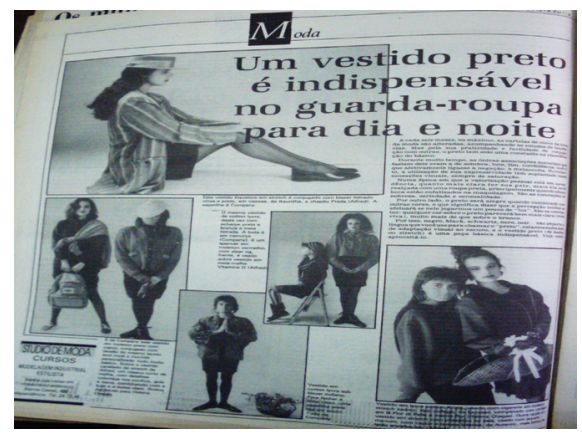

Figura 6. Sessão "Moda", editorial de modelos sugeridos para a estação.

Fonte: Zero Hora, n. 8.305, 1988.

7. Do inglês: roupas esporte. Estilo de roupas esportivas, especialmente utilizadas para a prática desportiva. 
Na Figura 6, da sessão "Moda" do jornal Zero Hora, é evidenciado o volume na parte superior dos looks, com peças amplas e ombros marcados, características da década de 80. A cintura é realçada, e a parte inferior abusa de calças coladas, meias-calças e saias curtas, mostrando as formas das pernas femininas.

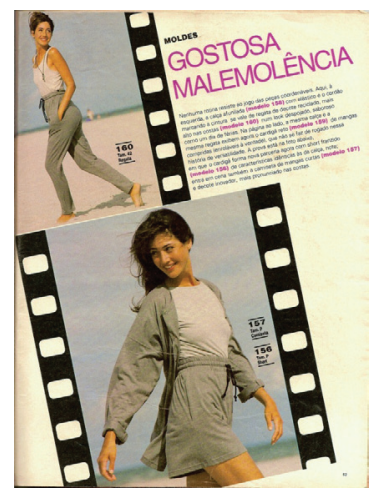

Figura 7. Editorial de moda revista

Manequim anos 90.

Fonte: Manequim, n. 399, 1993.

A modelo acima apresenta uma silhueta esguia e longilínea, tendo as formas ressaltadas pelo uso de tecidos leves. O ideal de magreza extrema é evidenciado pela modelagem seca das peças, a cintura alta marcada favorecendo modelos magras e altas (BAUDOT, 2002). As tendências são minimalistas: nota-se na Figura 7 um modelo sem muitos recortes, aplicações ou aviamentos. Os tecidos tecnológicos, muito utilizados, proporcionavam conforto, movimento e modelavam as formas influências do estilo esportivo e dos ideais de culto ao corpo.

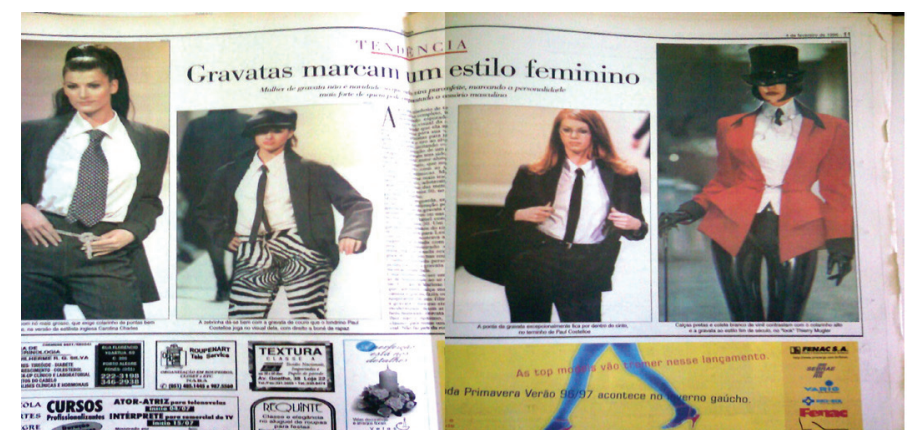

Figura 8. Sessão "Tendência" do caderno Donna ZH, editorial de modelos sugeridos para a estação.

Fonte: Zero Hora, n. II.125, 1996. 
A Figura 8, um editorial, evidencia a individualidade como forte tendência, sendo classificada como estilo de vanguarda. A "moda que vem das ruas" se tornou um vetor de lançamento de tendências, conforme afirma a reportagem da Figura 8. A silhueta continua esguia, o uso de tecidos tecnológicos, assim como o minimalismo, permanecem.

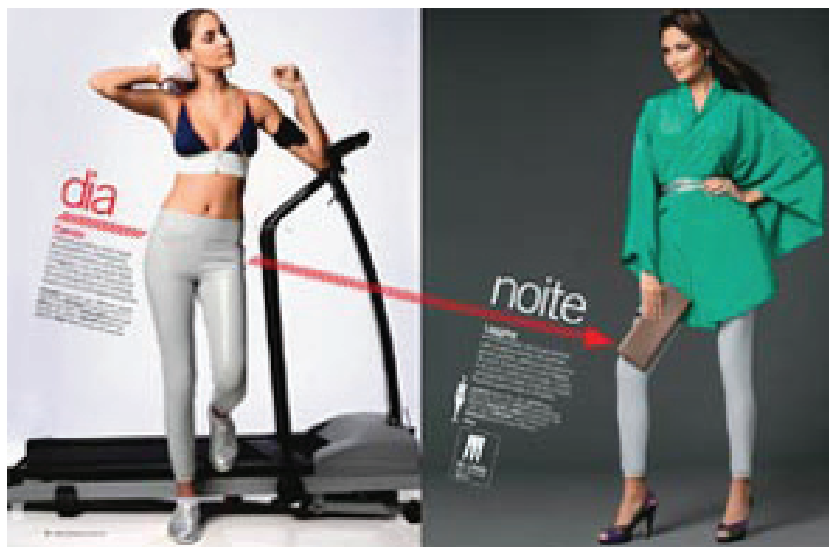

Figura 9. Editorial de moda revista Manequim anos 2000.

Fonte: http://manequim.abril.com.br/moda/historia-da-moda/ 50-anos-da-moda-no-brasil/2000-pecas-4.shtml.

culto ao corpo permanece na atualidade; na Figura 9 vê-se a adoção da roupa esporte, em uso não só no ambiente da academia ou na prática esportiva, mas incorporada ao dia-a-dia e em diversas ocasiões como uma peça de uso corriqueiro, ganhando as ruas. A valorização das formas corporais é vista com o uso de peças com tecidos de elastano ou tecidos leves e fluídos que ressaltem a estrutura corporal.

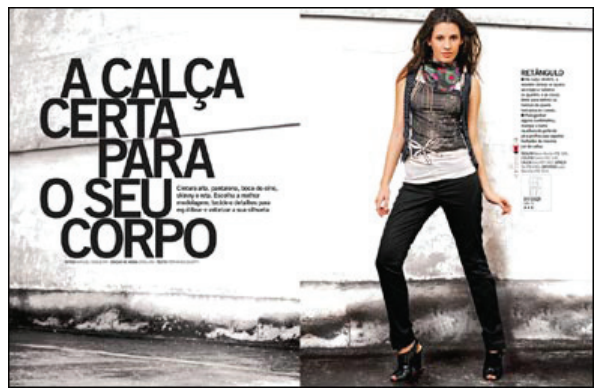

Figura I0. Editorial de moda revista Manequim anos 2000.

Fonte: http://manequim.abril.com.br/moda/historia-damoda/50-anos-da-moda-no-brasil/2000-pecas- I.shtml. 
A Figura I0, com título "A calça certa para o seu corpo" endossa a ideia do culto ao corpo, de um corpo bem modelado em harmonia com a roupa, que favoreça o biótipo. O foco se tornou o corpo, o ideal é possuir um corpo bem torneado com seios grandes, pernas compridas e finas, cintura fina e quadris estreitos. A moda se democratizou, sendo infinitas as possibilidades de escolha e de uso, porém, estas roupas são usadas especialmente para evidenciar as formas do corpo modeladas pela prática de esportes, adoção de hábitos saudáveis e por interferências cirúrgicas e estéticas. A silhueta eleita é um corpo modelado e estruturado pela roupa que o veste, valorizando cada linha e cada curva do corpo.

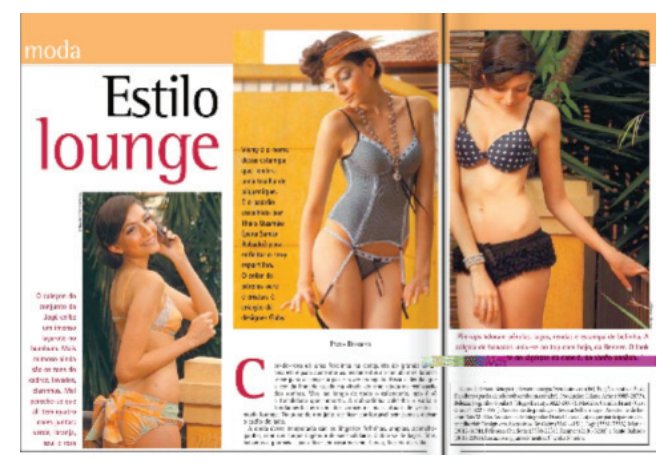

Figura I I. Sessão "Moda" do caderno Donna ZH, editorial de modelos sugeridos para a estação.

Fonte: Zero Hora, n. 15.189, 2008.

A Figura II apresenta um editorial de peças underwear, ${ }^{8}$ demonstrando a preocupação com o corpo, exaltado pela utilização de peças com finalidade estética, além da estritamente funcional. Observa-se que a estrutura física da modelo escolhida para as fotos segue um padrão de corpo tido como ideal neste período: magra, braços finos, seios grandes, quadril estreito e curvas moderadamente trabalhadas.

Outro aspecto a ser considerado é a estrutura corporal e sua evolução no decorrer dos anos. Ele (o corpo), um corpo cultural, ao ser modificado, incorporando novos valores estéticos, desempenha um papel cultural como meio de comunicação do indivíduo, querendo expressar algo com cada interferência sofrida. Esses valores estéticos da sociedade são alterados periodicamente, como, por exemplo, até 1950, de acordo com Mesquita (2004) a beleza era um "dom da natureza", "a partir daí, sua 'construção' passa a ser estimulada, não mais como um ganho a priori, mas sim como algo a ser trabalhado, batalhado, conquistado" (MESQUITA, 2004, p. 8I).

8. Termo em inglês que se refere a roupas íntimas. 
Noções de interferências exercidas pela roupa na silhueta podem ser percebidas através da observação de imagens apresentadas. Castilho (2009, p. 59) afirma que:

Ao buscar a relação estética entre a forma estrutural do corpo e a decoração têxtil, constatamos que ela pode ou não adequar-se à configuração anatômica do corpo. [...] podem ser encontrados inúmeros exemplos em que a estrutura é respeitada mesmo quando revestida por uma roupa, que, por sua vez, faz ressaltar o acordo instituído entre a estrutura física do corpo e o traje que o reveste. Nesses casos, fica evidente o caráter de mutação que o traje oferece ao corpo, assim como a necessidade contemporânea de mudança que lhe é imposta.

A reestruturação da silhueta, a partir da década de 60, não ocorre mais de maneira tão intensa como no século XIX, como, por exemplo, nos anos 20, com o uso dos achatadores de busto, ou na década de 1950, com cintura muito marcada.

Ainda falando da imagem estética atual, Goldenberg e Ramos (2007, p. 26) afirmam:

[... não apenas com atrizes ou modelos tal exigência de boa forma física se torna implacável. Por intermédio do cinema, da televisão, da publicidade e de reportagens de jornais e revistas, a exigência acaba atingindo os simples mortais, bombardeados cotidianamente por imagens de rostos e corpos perfeitos.

Os autores colocam esses veículos como grandes influenciadores e alguns dos principais difusores das tendências de moda, as quais são rapidamente aceitas, quase que em sua totalidade, sendo essas incorporadas ao dia-a-dia do indivíduo. $\bigcirc$ poder exercido pela mídia se dá pela produção de imagens "mágicas" e de desejo, e pela "venda" que a publicidade faz do poder e da influência que essas imagens emprestam. Esse jogo atua na esfera psicológica do sujeito, criando imagens e ideais que ele "necessita" alcançar em busca de seu pertencimento social, resultando em escolhas que satisfaçam suas necessidades. Sendo assim, tal análise acaba por endossar o poder que a moda exerce sobre os corpos femininos.

\section{CONSIDERAÇÕES FINAIS}

O corpo feminino se encontra em evidência na sociedade, além de ser um meio de autoafirmação para os indivíduos, os quais podem usá-los como passaporte para a inserção em grupos sociais, é "meio para atingir outros fins (expressão de status, de poder, de sedução, etc.)" (CALDAS, 2004, p. 80). Moda e corpo nunca estiveram tão ligados, a vestimenta se incorporou ao corpo de tal forma que se transformou "[...] numa segunda pele, ou seja, uma extensão dos meus próprios tecidos, 
da minha própria modelagem, como algo que já faz parte do meu corpo, faz parte de mim, enquanto dimensão sensório-motora" (CIDREIRA, 2005, p. II4).

A roupa é parte integrante da identidade do indivíduo, a forma como ele se mostra no mundo, pois a vestimenta é um complexo sistema de signos, assim como o corpo, que é considerado um território de manifestações não verbais, e a interrelação corpo-roupa parte da inserção de determinados valores provenientes da vestimenta que ressemantizam este corpo criando novas linguagens. Sendo assim, o corpo acompanha as transformações da moda. Pode-se perceber nas imagens selecionadas que as formas femininas foram, de fato, alteradas pelas roupas, pois ora eram disfarçadas por roupas que escondiam as formas das mulheres (década de 1960 e 1970), ora tornaram-se muito evidentes, não só revelando as silhuetas femininas, como exacerbaram certas partes do corpo - pernas longilíneas, seios avolumados ( a partir da década de 1980).

Essas mudanças não partem apenas das tendências de moda, mas é fruto de contextos histórico, social e cultural, os quais contribuíram para a evolução de um padrão corporal. De acordo com Cidreira (2005, p. I I), "as modalidades de interferência sobre o corpo são inúmeras e se diferenciam em função do grau de durabilidade", sendo divididas em modificações permanentes ou alopáticas. ${ }^{9}$ Pode-se dizer que interferências alopáticas são provindas do vestuário e as modificações permanentes provenientes de interferências estéticas e cirúrgicas.

A moda ultrapassa até mesmo os limites do fashion, constituindo-se em tecnologia específica de construção, sempre instável e fugaz, de "eus" ansiosos por meio da transfiguração das aparências do corpo, um corpo volátil que se transmuta à velocidade de um raio (SANTAELLA, 2004, p. I I8).

Portando significados para além da roupa, a moda como sistema oferece um discurso de corpo estratégico em sua expressão que, mediante este movimento de afetação corporal, torna a roupa um "capricho" do corpo, simulando e dissimulando conforme suas vontades.

A moda cria desejos, promove a insaciedade do indivíduo, que adota estratégias na busca por uma imagem ideal e de eternização do corpo e desta imagem. $\mathrm{Na}$ tentativa de saciar este desejo, os corpos se submetem aos desejos e vontades do indivíduo, sejam manifestadas em intervenções permanentes ou temporárias. $\bigcirc$ meio mais fácil, considerando a velocidade com que novas tendências são lançadas atualmente, é adotar novos shapes, provindos de decisões da moda, redesenhando, assim, a silhueta feminina com os subterfúgios do vestuário. Nas imagens

9. Caracterizam as tendências de curta duração. 
selecionadas, essas alterações são muito evidentes, pois pode-se perceber que tanto a revista especializada em moda quanto o jornal, sugerem formas físicas para as leitoras, ensinando-as, de certo modo, a disfarçarem ou evidenciarem aspectos físicos.

A moda-roupa remodela o corpo, mas não pelo modo de constrição e reestruturação física; as tendências submetem o corpo a moldar-se da melhor forma para poder portar as roupas e mostrar esse corpo. Anteriormente, apertava-se, ajustava-se, expandia-se o corpo através da roupa para obter e manter a silhueta desejada. Antigamente o vestuário era sinônimo de status e poder, hoje o corpo é quem reflete o status das pessoas, as diferencia.

O corpo sofre, sim, influências da moda, e ver-se-á que o corpo da mulher sofre mais, no entanto, não só as tendências de moda são responsáveis por essas mudanças, considerando a cultura como uma relação de valores morais e estéticos, pode-se dizer que estes mesmos valores culturais são grandes responsáveis por tais decisões, são imagens que a sociedade impõe.

As exigências estéticas modificam-se de tempos em tempos, criando novas tendências. Definido corpo como linguagem, afirma-se que, atualmente, é ele (o corpo) quem muda, o vestuário busca se adequar a ele, de modo que represente de forma coerente aquele corpo (CIDREIRA, 2005).

$\mathrm{Na}$ sociedade contemporânea tem-se um corpo fabricado e construído por ideais estéticos ditados pela própria sociedade. A reconstrução destes corpos é impulsionada por valores estéticos inerentes a essa sociedade, pela necessidade de embelezamento que o indivíduo sente, gerando em sequência um movimento de pertencimento dentro deste grupo. Sendo assim, esse indivíduo - mulher, principalmente - utiliza de artifícios a fim de se fazer aceito e, entre estas armas, encontra-se a moda.

\section{Changes in Female Silhouette: The Influence of Fashion}

ABSTRACT: This article reflects on the relation between fashion and female body, having as guiding principle the changes in female silhouette. It starts with the hypothesis that fashion creates wishes and needs by suggesting changes and adjustments to adapt the shape of the female body. It starts with a theoretical discussion about body and fashion, confronting then these two themes. Later there is a reflection on some pictures of magazine Manequim and newspaper Zero Hora, between the periods 1960 to 2000. It was observed that the media has really influenced the shape of women's bodies, which often must adapt the suggested formats of the clothes to wear fashionable clothes. KEYWORDS: Fashion, body, media, woman. 
Cambios en la silueta femenina: la influencia de la moda

RESUMEN: Este artículo reflexiona sobre la relación entre la moda y el cuerpo de la mujer, con los cambios de principio rector de la silueta de la mujer. Se inicia con la hipótesis de que la moda crea deseos y necesidades por lo que sugiere la parte que hace los cambios y ajustes, la adaptación de la forma del cuerpo femenino. Se inicia con una discusión teórica sobre el cuerpo y la moda, se enfrenta, entonces estos dos temas. Más adelante se encuentra la realización de la reflexión sobre algunas fotos de la revista Manequim y periódico Zero Hora, entre los períodos 1960 a 2000. Se observó que los medios de comunicación realmente han influido en las formas de los cuerpos de las mujeres, que a menudo deben adaptar los formatos sugeridos de la ropa para vestir ropa de moda.

PALABRAS CLAVE: Moda, el cuerpo, los medios de comunicación, la mujer.

\section{REFERÊNCIAS}

ANDRADE, M. M.; MEDEIROS, J. B. Comunicação em língua portuguesa: para os cursos de jornalismo, propaganda e letras. 3. ed. São Paulo: Atlas, 2004.

ANDRADE, S. S. Saúde e beleza do corpo feminino: algumas representações no Brasil do século XX. Movimento, Porto Alegre, v. 9, n. I, p. I 19 - 143, jan./abr. 2003.

ARAUJO, D. C.; SCHEMES, C. O corpo e a mídia: análise de uma campanha publicitária. Revista Digital, Buenos Aires, ano 12, n. I 18, 2008. Disponível em: < http://mww. efdeportes. com/efd I | 8/o-corpo-e-a-midia.htm>. Acesso em: 23 set. 2009.

BARNARD, M. Moda e comunicação. Rio de Janeiro, RJ: Rocco, 2003.

BARROS, D. R. et al. O corpo relacional. In: VARGAS, A. Reflexões sobre o corpo. Rio de Janeiro: Sprint, 1998.

BAUDOT, F. Moda do século. São Paulo: Cosac Naify, 2002.

BRAGA, J. Reflexões sobre moda: volume I. 2. ed. São Paulo: Anhembi Morumbi, 2005a.

BRAGA, J. Reflexões sobre moda: volume II. São Paulo: Anhembi Morumbi, 2005b.

CALANCA, D. História social da moda. São Paulo: Ed. Moutinho, 2008.

CALDAS, D. Observatório de sinais: teoria e prática da pesquisa de tendências. Rio de Janeiro: Senac, 2004.

CASTILHO, K. Moda e linguagem. 2. ed rev. São Paulo: Anhembi Morumbi, 2009.

CASTILHO, K.; MARTINS, M. M. Discurso da moda: semiótica, design, corpo. São Paulo: Anhembi Morumbi, 2005. 
CIDREIRA, R. Os sentidos da moda: vestuário, comunicação e cultura. São Paulo: Annablume, 2005.

CRANE, D. A moda e seu papel social: classe, gênero e identidade das roupas. São Paulo: Senac, 2006.

DEL PRIORE, M. Corpo a corpo com a mulher: pequena história das transformações do corpo feminino no Brasil. São Paulo: Senac, 2000.

ETCOFF, N. A lei do mais belo: a ciência da beleza. Rio de Janeiro: Objetiva, 1999.

FISCHER-MIRKIN, T. O código do vestir: os significados ocultos da roupa feminina. Rio de Janeiro: Rocco, 2001 .

GARCIA, C.; MIRANDA, A. Moda é comunicação: experiências, memórias, vínculos. São Paulo: Anhembi Morumbi, 2005.

GARCIA, W. Corpo, mídia e representação: estudos do contemporâneo. São Paulo: Pioneira Thomson Learming, 2005.

GOLDENBERG, M.; RAMOS, M. A civilização das formas: $O$ corpo como valor. In: GOLDENBERG, M. (Org.). Nu \& vestido: dez antropólogos revelam a cultura do corpo carioca. Rio de Janeiro: Record, 2007.

HISTORIA DA MODA. Disponível em: http://manequim.abril.com.br/moda/historia-damoda/50-anos-da-moda-no-brasil// 980-pecas-6.shtml. Acesso em: 05 abr. 2010.

HISTORIA DA MODA. Disponível em: http://manequim.abril.com.br/moda/historia-da-moda/50-anos-da-moda-no-brasil/2000. Acesso em: 05 abr. 2010.

KAKESHITA, I. S. Adaptation and validation of a figure rating scales for brazilian children and adults. 2008. 96 f. Tese (Doutorado) - Faculdade de Filosofia Ciências e Letras de Ribeirão Preto, Universidade de São Paulo, Ribeirão Preto, 2008.

KEHL, M.; BUCCl, E. Videlogias: ensaio sobre televisão. São Paulo: Boitempo, 2004.

LAVER, J. A roupa e a moda: uma história concisa. São Paulo: Cia de Letras, 1989.

LIPOVETSKY, G. Os tempos hipermodernos. São Paulo: Barcarolla, 2004.

MANEQUIM. São Paulo, n. 399, mar. 1993.

MANEQUIM. São Paulo, n. 180, dez. 1974.

MESQUITA, C. Moda contemporânea: quatro ou cinco conexões possíveis. São Paulo: Anhembi Morumbi, 2004.

MIRANDA, A. P. Consumo de moda: a relação pessoa-objeto. São Paulo: Estação das Letras e Cores, 2008. 
MORENO, R. A beleza impossível: mulher, mídia e consumo. São Paulo: Ágora, 2008.

MOUTINHO, M. R.; VALENÇA, M. T. A moda no século XX. Rio de Janeiro: Ed. Nacional, 2000.

NERY, M. L. A evolução da indumentária: subsídios para criação de figurino. Rio de Janeiro:

Ed. MOUTINHO; VALENÇA Nacional, 2004.

SANT'ANNA, M. R. Teoria da moda: sociedade, imagem e consumo. 2. ed. São Paulo: Estação das Letras e Cores, 2009.

SANTAELLA, L. Corpo e comunicação: sintoma da cultura. São Paulo: Paulus, 2004.

SILVA, A. M. Corpo, ciência e mercado: reflexões acerca da gestação de um novo arquétipo de felicidade. São Paulo: Autores Associados; Florianópolis: Ed. da UFSC, 2001.

SILVA, T. T. (Org.). Identidade e diferença: a perspectiva dos estudos culturais. Petrópolis: Vozes, 2000.

ZERO HORA. Porto Alegre, n. 4.317, 18 jun. 1977.

ZERO HORA. Porto Alegre, n. 597, 1966.

ZERO HORA. Porto Alegre, n. 4556, 1978.

ZERO HORA. Porto Alegre, n. 8.305, 1988.

ZERO HORA. Porto Alegre, n. I I. I25, 1996.

ZERO HORA. Porto Alegre, n. 15. I89, 2008.

Recebido em: 29 set. 201 I

Aprovado em: 09 dez. 20 I I

Endereço para correspondência:

Denise Castilhos de Araujo

Rua Caxambu, 447, ap. 702

Bairro Vila Nova 